Please do not remove this page

RMIT

UNIVERSITY

\title{
The prediction of flanking sound transmission below the critical frequency
}

Davy, John; Mahn, Jeffrey; Guigou-Carter, Catherine; Villot, Michel

https://researchrepository.rmit.edu.au/esploro/outputs/9921858437801341/filesAndLinks?institution=61RMIT_INST\&index=null

Davy, J., Mahn, J., Guigou-Carter, C., \& Villot, M. (2012). The prediction of flanking sound transmission below the critical frequency. The Journal of the Acoustical Society of America, 132(4), 2359-2370.

https://doi.org/10.1121/1.4746945

Document Version: Accepted Manuscript

Published Version: https://doi.org/10.1121/1.4746945

Repository homepage: https://researchrepository.rmit.edu.au

Copyright (2012) Acoustical Society of America. This article may be downloaded for personal use only. Any other use requires prior permission of the author and the Acoustical Society of America.

Downloaded On 2023/04/26 23:29:31 +1000 
The prediction of flanking sound transmission below the critical frequency ${ }^{\mathrm{a}}$

\author{
John L. Davy ${ }^{\text {bc }}$
}

School of Applied Sciences, Royal Melbourne Institute of Technology (RMIT) University, GPO

Box 2476V Melbourne, Victoria 3001, Australia

Jeffrey P. Mahn

University of Canterbury, Mechanical Engineering, Private Bag 4800, Christchurch 8140, New

$$
\text { Zealand }
$$

Catherine Guigou-Carter

Centre Scientifique et Technique du Bâtiment (CSTB), Département Acoustique et Éclairage, 24

Rue Joseph Fourier, 38400 Saint Martin d'Hères, France

Michel Villot

Centre Scientifique et Technique du Bâtiment (CSTB), Département Acoustique et Éclairage, 24

Rue Joseph Fourier, 38400 Saint Martin d'Hères, France

Running title: Flanking sound transmission

${ }^{a}$ Portions of this work were presented in "Uncertainty of the estimation of resonant transmission loss below the critical frequency," COST FP0702 Workshop, Delft, Netherlands, 4 November 2010.

${ }^{\mathrm{b}}$ Author to whom correspondence should be addressed. Electronic mail: john.davy@rmit.edu.au ${ }^{c}$ Current address: CSIRO Materials Science and Engineering, PO Box 56 Highett Victoria 3190, Australia. 
Although reliable methods exist to predict the apparent sound reduction index of heavy, homogeneous isotopic building constructions, these methods are not appropriate for use with lightweight building constructions which typically have critical frequencies in or above the frequency range of interest. Three main methods have been proposed for extending the prediction of flanking sound transmission to frequencies below the critical frequency. The first method is the direct prediction which draws on a database of measurements of the flanking transmission of individual flanking paths. The second method would be a modification of the method in existing standards. This method requires the calculation of the resonant sound transmission factors. However, most of the approaches proposed to calculate the resonant sound transmission factor work only for the case of single leaf homogeneous isotropic building elements and therefore are not readily applicable to complex building elements. The third method is the measurement or prediction of the resonant radiation efficiency and the airborne diffuse field excited radiation efficiency which includes both the resonant and the non-resonant radiation efficiencies. The third method can currently deal with complex building elements if the radiation efficiencies can be measured or predicted. This paper examines these prediction methods.

PACS numbers: 43.55.Rg, 43.55.Ti, 43.40.Rj, 43.20.Rz 


\section{INTRODUCTION}

Parts 1 and 2 of the EN 12354 (ISO 15712) (2005a; b) series of standards describe methods for predicting airborne and impact flanking sound transmission. These methods are only applicable to monolithic homogeneous isotropic building elements above the critical frequency (Hongisto, 2001; Gerretsen, 2003). There is great interest worldwide in applying the prediction of the apparent sound transmission to lightweight building elements which typically have critical frequencies in or above the frequency range of interest. The main purpose of this paper is to present the results of new theoretical research into why the different methods, which have been proposed to extend the EN 12354 method to below the critical frequency, give such different results, and to recommend, on the basis of theoretical grounds, which are the best methods to use. Three main approaches have been proposed for extending the predictions to frequencies below the critical frequency and to more complicated building elements.

The first proposed approach is the direct measurement of the flanking transmission factors of each transmission path for typical constructions and the establishment of a database of these flanking transmission factors. The direct method can work with complex building elements and avoids problems such as the non-diffuse vibratory fields (Brunskog and Chung, 2011) which are typical of lightweight constructions.

The second approach is the modification of the existing EN 12354 series of standards to adapt it for use with complex structures typical of lightweight constructions. The EN 12354 predictions require the calculation of the resonant sound transmission factors of the building elements under evaluation. The calculation of the resonant sound transmission factors presents a problem when applying this approach to lightweight elements which typically have critical frequencies in or above the frequency range of interest. The methods which have been proposed 
in the literature for the calculation of the resonant sound reduction index of lightweight elements will only work with single leaf, homogeneous, isotropic elements with the exception of the correction factor proposed by the Centre Scientifique et Technique du Bâtiment (CSTB). Mahn and Pearse (2008b) and Mahn and Stevenson (2008) tried a number of different methods of determining the resonant sound transmission factors of lightweight elements and found that the different methods resulted in a wide range of values, some of which were invalid.

Most lightweight building elements are more complex than single leaf, homogeneous, isotropic elements. Ribs such as studs and joists complicate the theoretical calculations by providing a structural transmission path between separate wall leaves. The EN12354 (ISO, 2005a; b) method does not make clear whether it is the double leaf wall or just one of its leaves which is to be used in the calculation of the resonant transmission loss.

The third approach is the measurement or the prediction of the airborne diffuse field excited radiation efficiency and the resonant radiation efficiency. These values are then used along with the airborne noise excited velocity level difference to predict the flanking sound reduction index of complex building elements. This approach will be referred to as the CSTB prediction method in this paper.

Each of the approaches will be examined in this paper and the advantages and disadvantages discussed. It should be noted that in the published literature relating to the topics considered in this paper, the terms "free" and "resonant" are used interchangeably to describe the vibration, the sound transmission factor, the sound insulation, the sound reduction index and the sound transmission loss. Similarly, the terms "forced" or "non-resonant" are also used interchangeably to describe the same terms. In this paper the terms "resonant" and "non- 
resonant" will be used in order to avoid having to use both interchangeable terms. However, the authors believe that there is nothing wrong with the use of the other interchangeable terms.

\section{DIRECT PREDICTION METHOD}

The most direct method of predicting the apparent sound transmission factor is to establish a database of measured flanking sound transmission factors for different combinations of elements and junctions. The measurement of the flanking sound transmission of each path could be made in a dedicated facility by using sound intensity to measure the sound transmission for the flanking elements (ISO, 2003) or by shielding all of the flanking elements other than the ones being measured. If the flanking normalized level difference $D_{n f}$ is measured in the laboratory situation for lightweight building elements with high internal damping, then the in situ flanking sound reduction index $R_{i j}$ is given by ISO 15712-1 (ISO, 2005a)

$$
R_{i j}=D_{n f}+10 \log _{10} \frac{S_{0} l_{i j, l a b}}{A_{0} l_{i j}},
$$

where the structural reverberation times have been ignored because of the high internal damping loss factors. In this equation, $S_{0}$ is the area of the common building element between the two rooms, $A_{0}$ is the normalized sound absorption area of $10 \mathrm{~m}^{2}$ and $l_{i j, l a b}$ and $l_{i j}$ are the length of the junction between building elements in the laboratory and in situ, respectively. The apparent sound reduction index of a new construction can then be predicted by using the database to compile the transmission loss of the direct transmission path and the flanking sound transmission factors of each of the flanking transmission paths.

The direct prediction method is being used by the National Research Council of Canada based on the database of measurements made at the flanking facility in Ottawa (Quirt, 2009). This method has the advantage that measured values are used and therefore the method is not limited by the assumptions made for the EN12354 method (ISO, 2005a; b) including that the 
critical frequencies of the elements are below the frequency range of interest and that the elements support diffuse vibratory fields. However, a major difficulty with this approach is the extension of the predictions to the low frequencies since it is difficult to adequately shield alternative flanking transmission paths during the measurements at the low frequencies. Measurements made using sound intensity will have the same problem since shielding may be needed in the presence of strong flanking contributions from other elements. Another problem is that it is not possible to predict the performance of constructions which have not already been tested. Lastly, the database used for the direct predictions will have to be very large to be used for a large number of different element and junction constructions. This is because each combination of structure, junction and structure needs to be measured separately and different directions of the reinforcing ribs relative to the junction count as different structures.

\section{THE EN12354 PREDICTION METHOD}

The second method of calculating the flanking sound transmission factors of lightweight building constructions involves modifying the existing EN 12354 method (ISO, 2005a; b) by specifying how to calculate the resonant sound transmission factor below the critical frequency. According to Gerretsen (1979), the flanking transmission factor can be calculated according to

$$
\tau_{i j}=\tau_{r, i} d_{r, i j} \frac{\sigma_{r, j}}{\sigma_{r, i}} \frac{S_{j}}{S_{0}} .
$$

where $\tau_{i j}$ is the flanking sound transmission factor between building elements $i$ and $j, \tau_{r, i}$ is the resonant sound transmission factor of building element $i, \sigma_{r, i}$ is the radiation efficiency of building element $i$ and $S_{j}$ is the surface area of element $j$, and the resonant vibration reduction factor $d_{r, i j}$ is the ratio of the spatially averaged mean squared surface velocities $v_{r, j}^{2}$ and $v_{r, i}^{2}$ of building elements $j$ and $i$ when the vibration of building element $i$ is only resonant such that: 


$$
d_{r, i j}=\frac{v_{r, j}^{2}}{v_{r, i}^{2}}
$$

Everywhere $v^{2}$ occurs in this paper it should be read as $\left\langle v^{2}\right\rangle$ where the angular brackets denote averaging over time and spatial averaging over the appropriate surface of the building element.

The EN12354 estimate of the flanking transmission factor $\tau_{E N 12354}$ between elements $i$ and $j$ assumes reciprocity between the calculated flanking transmission factor terms in each direction to exclude the radiation efficiency terms from Eq. (2) such that (Nightingale, 1995)

$$
\tau_{E N 12354} \approx \tau_{i j} \approx \tau_{j i} \approx \sqrt{\tau_{i j} \tau_{j i}}=\sqrt{\tau_{r, i} \tau_{r, j}} \sqrt{d_{r, i j} d_{r, j i}} \frac{\sqrt{S_{i} S_{j}}}{S_{0}}
$$

According to ISO10848 (ISO, 2006), the spatially averaged mean square velocity used to calculate the vibration reduction factor is generally measured on the non-excited face of the source element and on the radiating face of receiving element. In the case of homogeneous, isotropic, finite building elements, the side on which the measurements are made is irrelevant, but in the case of double-leaf constructions, attention to the measurement surface is important. However, it should be noted that there is still some debate about which surface should be used to make the measurements of the spatially averaged mean square velocity in the case of double-leaf elements.

The determination of the resonant sound transmission factors in Eq. (4) presents a problem with applying the EN12354 method below the critical frequency. In the case of heavy, monolithic structures with critical frequencies below the frequency range of interest, the resonant transmission factor may be assumed to be that measured in the laboratory. However, this is not the case for lightweight elements with critical frequencies in or above the frequency range of interest. The EN 12354 standard does not currently give guidance for the calculation of the 
resonant sound transmission factors and there is disagreement in the literature regarding which calculation method should be employed. Furthermore, the EN 12354 method does not currently define whether the resonant sound reduction index should be calculated for the entire wall construction or for the single leaves.

A number of different methods for calculating the resonant sound transmission factors have been proposed in the literature. Most of the literature assumes that the building elements are single leaf finite homogeneous isotropic panels. Therefore, in the discussion of the calculation of the resonant transmission factor, it will usually be assumed that the building elements are single leaf finite homogeneous isotropic panels. This is a very serious restriction. Most building elements with high critical frequencies will be complex structures.

In this paper, the non-resonant sound transmission factor and the non-resonant velocity are approximated by their values that would occur if the panel was completely limp and was excited by a diffuse incidence airborne sound field. The resonant sound transmission factor and the resonant velocity are the difference between their total values and their non-resonant values when excited by an airborne diffuse incidence sound field.

This definition of non-resonant velocity is what is effectively used in EN12354 (ISO, 2005a), in statistical energy analysis (SEA) approach of Crocker and Price (1969) and by Gerretsen (2007). It is a practical approximation to the particular integral of the bending wave partial differential equation of a single leaf homogeneous isotropic wall below the critical frequency which is more appropriate to use in this situation than Sewell's approximate correction factor (1970). It has no relationship to the particular integral at and above the critical frequency and is different from the approximation used by Sewell (1970), Rudder (1985), Leppington $e$ al . 
(1987) and Lee and Ih (2004) below the critical frequency. These authors use Sewell's (Sewell, 1970) approximate correct factor of

$$
\frac{1}{\left[1-\left(\frac{f}{f_{c}}\right)^{2}\right]^{2}}
$$

which accounts for the approach of the frequency $f$ to the critical frequency $f_{c}$ from below.

Sewell's approximate correction factor is an approximation because it is only completely correct if all the sound is incident at grazing angles of incidence, and if damping and radiation losses are ignored.

It is not clear if these definitions can be applied to more complicated building elements. This, together with the disagreement in the literature on the definitions, suggests that the use of resonant sound transmission factors for complex building elements is best avoided completely if possible.

The methods which have been proposed to calculate the resonant sound transmission factor can be grouped into three categories: subtraction methods, correction factors and theoretical predictions.

\section{A. Subtraction of the predicted non-resonant sound transmission factor}

The simplest method to obtain the resonant sound transmission factor is to subtract the predicted non-resonant sound transmission factor from the measured total sound transmission factor (Gerretsen, 2007). However, the subtraction method has a number of significant limitations. The sound reduction index measured according to ISO140 has a standard deviation of reproducibility as high as $9 \mathrm{~dB}$ in the $100 \mathrm{~Hz} \mathrm{1/3}$ octave band (ISO, 1991). Below the critical frequency, the resonant sound transmission factor can be much smaller than the non-resonant 
sound transmission factor. Because of the measurement and prediction uncertainties, the calculated value can produce non-physical negative values (Mahn and Pearse, 2008b).

Another problem is the prediction of the non-resonant sound transmission factors of typical lightweight cavity wall building elements. For instance, stud walls have significant radiation from bending wave near fields. Are bending wave near fields resonant and/or non-resonant? Even for single leaf homogeneous isotropic building elements, different theories produce different predictions for the non-resonant sound transmission factor. Does only one leaf of a multi-leaf wall need to be considered?

Mahn and Pearse (2008b) measured the sound transmission factor of a $1.6 \mathrm{~mm}$ thick steel panel from $100 \mathrm{~Hz}$ to $5 \mathrm{kHz}$ and used various theories to predict the non-resonant sound transmission factor and subtracted it from the total sound transmission factor in order to obtain the resonant sound transmission factor. The critical frequency was in the $8 \mathrm{kHz}$ band and the surface density was $12.51 \mathrm{~kg} / \mathrm{m}^{2}$. The dimensions of the panel were $0.950 \mathrm{~m} \times 1.546 \mathrm{~m}$. The source room was a $217 \mathrm{~m}^{3}$ reverberation room and sound intensity was used on the receiving room side.

The study found that the theory of Rudder (1985) produced no positive values. The theories of Leppington et al. (1987) and Lee and Ih (2004) produced positive values at 100 to $160 \mathrm{~Hz}$ and $315 \mathrm{~Hz}$. Sewell's (1970) theory produced positive values at 100, 160, and $315 \mathrm{~Hz}$. Gerretsen's (2007) theory produced positive values at 100, 160, 315, 2500, and $5000 \mathrm{~Hz}$. The field incidence mass law produced positive values from 1600 to $5000 \mathrm{~Hz}$. The normal incidence mass law produced positive values at all frequencies.

Mahn and Pearse (2008b) also made measurements on $4 \mathrm{~mm}$ medium density fiberboard (MDF). The critical frequency was in the $8 \mathrm{kHz}$ band and the surface density was $3.2 \mathrm{~kg} / \mathrm{m}^{2}$. The 
dimensions of the panel were $0.946 \mathrm{~m} \times 1.545 \mathrm{~m}$. Rudder's (1985) theory produced no positive values. The theories of Leppington et al. (1987), Lee and Ih (2004) and Sewell (1970) produced positive values at $100 \mathrm{~Hz}$. Gerretsen's (2007) theory produced positive values at 100 and 5000 Hz. The field incidence mass law produced positive values from 3150 to $5000 \mathrm{~Hz}$. The normal incidence mass law produced positive values from 250 to $5000 \mathrm{~Hz}$. It should be noted that the results given here are different from the results given in Mahn and Pearse (2008b). An error in the calculation of the non-resonant radiation efficiency has been discovered and corrected (Mahn, 2010).

Only those theories which do not use Sewell's (1970) correction factor, Eq. (5), for the approach of the frequency to the critical frequency produced any positive values at the high frequency end. Ignoring the unrealistic normal incidence mass law, only those theories which use a non-resonant radiation efficiency which varies with frequency produced any positive values at the low frequency end.

However Gerretsen (2007) has applied the subtraction method without obtaining negative values with octave band measurements from 63 to $4000 \mathrm{~Hz}$. The negative values were avoided by limiting the correction to a maximum of $10 \mathrm{~dB}$ (Gerretsen private communication). The materials included in the study were $70 \mathrm{~mm}$ calcium-silicate $\left(130 \mathrm{~kg} / \mathrm{m}^{2}\right.$ with $\left.f_{c} \approx 160 \mathrm{~Hz}\right), 70$ mm gypsum blocks $\left(66 \mathrm{~kg} / \mathrm{m}^{2}\right.$ with $\left.f_{c} \approx 500 \mathrm{~Hz}\right), 10 \mathrm{~mm}$ glazing $\left(25 \mathrm{~kg} / \mathrm{m}^{2}\right.$ with $\left.f_{c} \approx 1250 \mathrm{~Hz}\right)$ and $12.5 \mathrm{~mm}$ gypsum board with studs $\left(15 \mathrm{~kg} / \mathrm{m}^{2}\right.$ with $\left.f_{c} \approx 3150 \mathrm{~Hz}\right)$. Note that these materials all have higher surface densities and lower critical frequencies than Mahn and Pearse's (2008b) materials. Even if the subtraction method produces no negative values, the positive values will still be very uncertain. Thus it appears that the subtraction method is not suitable to calculate the resonant sound transmission factor. 


\section{B. The correction factor}

If $\tau_{n r}$ and $\tau_{r}$ are the non-resonant and resonant sound transmission factors, following from Mahn and Pearse (2008b), the correction factor is

$$
C=\frac{\tau}{\tau_{r}}=1+\frac{\tau_{n r}}{\tau_{r}}
$$

and the resonant sound transmission factor can be calculated from the total sound transmission factor $\tau$,

$$
\tau_{r}=\frac{\tau}{C} .
$$

The use of resonant sound transmission factors depends on the assumption that the non-resonant vibration transmitted at a junction of building elements is insignificant compared to that transmitted by the resonant vibration. Nevertheless a number of correction factor methods have been proposed which differ only in the values for the two ratios that they use.

\section{The CSTB correction factor}

The temporal and spatial mean squared velocity $v_{a}^{2}$ of a diffuse airborne field excited homogeneous isotropic finite building element is the sum of the non-resonant mean squared velocity $v_{n r}^{2}$ and the resonant mean squared velocity $v_{r}^{2}$ (Villot, 2002), if these two velocities are uncorrelated and have different wave numbers, such that

$$
v_{a}^{2}=v_{n r}^{2}+v_{r}^{2} .
$$

This will normally be the case, except above the critical frequency when coincidence occurs. The radiated sound intensity $I$ on one side of the panel divided by the characteristic impedance of air is

$$
\frac{I}{\rho_{0} c}=v_{n r}^{2} \sigma_{n r}+v_{r}^{2} \sigma_{r}=v_{a}^{2} \sigma_{a},
$$


where $\sigma_{r}$ and $\sigma_{n r}$ are the resonant and non-resonant radiation efficiencies, $\sigma_{a}$ is the airborne diffuse field excited radiation efficiency inclusive of both the resonant and non-resonant components, $\rho_{0}$ is the ambient density of air and $c$ is the speed of sound in air. Crocker and Price (1969) and others have shown that the ratio $r$ of the resonant mean squared velocity to the nonresonant mean squared velocity for a single leaf homogeneous isotropic building element is

$$
r=\frac{v_{r}^{2}}{v_{n r}^{2}}=\frac{\pi}{4} \frac{f_{c}}{f} \frac{\sigma_{r}}{\eta}
$$

where $\eta$ is the total damping loss factor. Equations (8), (9) and (10) can be solved to produce:

$$
\sigma_{a}=\frac{r \sigma_{r}+\sigma_{n r}}{r+1}
$$

and

$$
\frac{\sigma_{r}}{\sigma_{a}}=\frac{r+1}{r+\sigma_{n r} / \sigma_{r}} .
$$

Alternatively, if the values of the three radiation efficiencies are known, the value of the ratio of the resonant mean squared velocity to the non-resonant mean squared velocity can be calculated using

$$
r=\frac{v_{r}^{2}}{v_{n r}^{2}}=\frac{\sigma_{n r}-\sigma_{a}}{\sigma_{a}-\sigma_{r}} .
$$

The value of the ratio of the resonant mean squared velocity to the diffuse airborne excited mean squared velocity can also be calculated.

$$
\frac{v_{r}^{2}}{v_{a}^{2}}=\frac{\sigma_{n r}-\sigma_{a}}{\sigma_{n r}-\sigma_{r}} .
$$

Unfortunately, as will be seen later, the experimental use of Eq. (14) can produce non-physical negative values which cannot be converted to decibels.

Equations (12) and (6) give (Villot and Guigou-Carter, 2006) 


$$
C=\frac{\tau}{\tau_{r}}=1+\frac{\tau_{n r}}{\tau_{r}}=1+\frac{\sigma_{n r}}{r \sigma_{r}}=1+\frac{\sigma_{n r}}{\sigma_{r}} \frac{\sigma_{a}-\sigma_{r}}{\sigma_{n r}-\sigma_{a}}=\frac{\sigma_{a}}{\sigma_{r}} \frac{\sigma_{n r}-\sigma_{r}}{\sigma_{n r}-\sigma_{a}}
$$

The diffuse field airborne excited radiation efficiency and the resonant radiation efficiency (possibly with a near field correction) can be measured directly. Currently, the non-resonant radiation efficiency can only be calculated for single leaf homogeneous isotopic building elements. It is possible to measure the non-resonant radiation efficiency using near field acoustical holography and wave number separation. However, very few laboratories have the facilities to make such measurements and the measurements are very time consuming.

One way of overcoming this difficulty is to assume that the diffuse field airborne excited radiation efficiency and the resonant radiation efficiency are very small compared to the nonresonant radiation efficiency. In this case Eq. (15) becomes (Villot and Guigou-Carter, 2006)

$$
C=\frac{\tau}{\tau_{r}}=\frac{\sigma_{a}}{\sigma_{r}}
$$

Another way of overcoming the difficulty of the calculation of the non-resonant radiation efficiency is to assume that $\sigma_{n r} \approx 1$ (Villot and Guigou-Carter, 2006). For a single leaf homogeneous isotropic building element, this is equivalent to assuming that, below about half the critical frequency, the diffuse field sound transmission factor is equal to the infinite panel $45^{\circ}$ incidence sound transmission factor. This approach produces the following equation.

$$
C=\frac{\tau}{\tau_{r}} \approx 1+\frac{1}{\sigma_{r}} \frac{\sigma_{a}-\sigma_{r}}{1-\sigma_{a}}=\frac{\sigma_{a}}{\sigma_{r}} \frac{1-\sigma_{r}}{1-\sigma_{a}} .
$$

If the diffuse field airborne excited radiation efficiency and the resonant radiation efficiency are assumed to be very small compared to 1, Eq. (17) reduces to Eq. (16). Equations (16) and (17) can be evaluated using measured values and therefore are the only correction factors which are currently suitable for use with complex structures. 
FIG. 1 shows the ratio $\left(\sigma_{n r}-\sigma_{a}\right) /\left(\sigma_{n r}-\sigma_{r}\right)$ of Eq. (14) for a single leaf $13 \mathrm{~mm}$ gypsum plaster board wall mounted on wood studs $\left(9 \mathrm{~kg} / \mathrm{m}^{2}\right.$ with $\left.f_{c} \approx 3150 \mathrm{~Hz}\right)$ measuring 4.18 by $2.47 \mathrm{~m}$. The term $\sigma_{n r}$ has been calculated by setting it to the value 1 , by using the theory of (Sewell, 1970) and by using the spatial windowing technique (Villot et al., 2001). EN 12354 (ISO, 2005a) specifies that the radiation efficiency is limited to a maximum value of two, but this limitation has not been applied to the data in the figure. It is expected that the ratio graphed in FIG. 1 should be between 0 and 1. For Sewell's theory and spatial windowing, this is the case from $50 \mathrm{~Hz}$ to 2.5 $\mathrm{kHz}$ and all the values lie in the range from 0.54 to 1.15 . The approximation of setting $\sigma_{n r}$ to one works well at the lower frequencies but produces negative ratios at 1.6 and $2 \mathrm{kHz}$ and a large positive value at $2.5 \mathrm{kHz}$. Therefore, the approximation is not suitable for use across the entire frequency range.

FIG. 2 shows the same information as FIG. 1 but for a double layer single leaf wall made of $13 \mathrm{~mm}$ gypsum plaster board $\left(9 \mathrm{~kg} / \mathrm{m}^{2}\right.$ with $\left.f_{c} \approx 3150 \mathrm{~Hz}\right)$ and $16 \mathrm{~mm}$ Oriented Strand Board (OSB) $\left(10 \mathrm{~kg} / \mathrm{m}^{2}\right.$ with $\left.f_{c} \approx 1600 \mathrm{~Hz}\right)$ and mounted on wood studs . Sewell's theory and spatial windowing produce values in the range from 0.20 to 1.01 . The approximation of $\sigma_{n r}=1$ works well at the lower and at the higher frequencies but produces negative ratios at 315,400 , and 500 Hz. Therefore, the approximation is not suitable for use across the entire frequency range.

FIG. 3 shows the same information as FIG. 1 and FIG. 2, but for a wooden floor made of $22 \mathrm{~mm}$ chipboard on I beam joists $\left(14 \mathrm{~kg} / \mathrm{m}^{2}\right.$ with $\left.f_{c} \approx 2000 \mathrm{~Hz}\right)$. All three methods of calculating the forced radiation efficiency produce ratios which agree reasonably well with each other and which appear to behave reasonably well from 50 to $630 \mathrm{~Hz}$. The ratios range from 0.78 to $1.21 \mathrm{in}$ this frequency range. Above $630 \mathrm{~Hz}$, the three different methods produce results which are very different from each other and which include negative results and results which are very much 
greater than 1 . Therefore, none of the three different methods appears to be suitable for use above $630 \mathrm{~Hz}$ with this particular building element. The data for the airborne excited and mechanically excited radiation efficiencies used to calculate the results graphed in figures 1 to 3 are experimentally measured using near field acoustical holography as described in Villot and Guigou-Carter (2000).

\section{The Nightingale correction factor $\xi$}

Nightingale (1995) measured the ratio of the resonant velocity $v_{r}{ }^{2}$ to the total airborne diffuse field excited velocity $v_{a}^{2}$ which radiated the same sound power, by exciting the building element via a connected building element which was excited mechanically and with an airborne diffuse sound field. Unfortunately he multiplied the ratio by

$$
\frac{2}{\pi} \frac{f}{f_{c}} \eta
$$

before using it as a correction factor. The effects of this multiplication can been seen in Figure 7 of Mahn and Pearse (2008b) which shows the resonant sound reduction index calculated using Nightingale's correction factor differs significantly from the other calculated values, especially at the low frequencies. Nightingale's derivation of his correction factor appears to contain a number of erroneous assumptions. Because of these errors the use of Nightingale's correction factor is not recommended.

\section{Metzen's correction factor}

This correction factor has been proposed by Metzen (2004) and Gerretsen (2007). It should be noted that both Metzen's and Gerretsen's formulas for this correction factor contain errors. The correct version as found in Mahn and Pearse (2008b) is:

$$
C=1+\frac{\pi f \eta l_{1}}{\sigma_{r} c} \sqrt{\frac{f_{c}}{f}}
$$


where, $l_{1}$ is the largest dimension of the element $l_{1} \times l_{2}$.

For a square panel, the use of the Metzen correction factor is equivalent to using the value of $r$ from Eq. (10), assuming that $\sigma_{n r} \approx 1$ and the use of the following low frequency approximation to the resonant radiation efficiency given in the first two editions of Cremer and Heckl's (1973) textbook,

$$
\sigma_{r} \approx \frac{U \lambda_{c}}{\pi^{2} S} \sqrt{\frac{f}{f_{c}}} \text { for } f<<f_{c}
$$

where $U$ is the perimeter, $S$ is the area, and $\lambda_{c}$ is the wavelength of sound in air at the critical frequency $f_{c}$. This expression is a very low frequency approximation to the well known result of Maidanik (1962; Vér and Holmer, 1971) and Leppington et al. (1982) below the critical frequency. If this correction factor is to be used, the authors suggest that it would be better to use a more exact diffuse field incidence non-resonant radiation efficiency [see Davy (2009) for a discussion of some possible formulas] and the more exact result for the resonant radiation efficiency derived by Maidanik (1962; Vér and Holmer, 1971) and Leppington et al. (1982). This would yield

$$
C=1+\frac{4 f \eta \sigma_{n r}}{\pi f c \sigma_{r}^{2}},
$$

where $\sigma_{r}$ is given by Maidanik (1962; Vér and Holmer, 1971) and Leppington et al. (1982).

\section{Annex B of EN 12354 part 1 (ISO 15712 Part 1) correction factor}

Gerretsen (2007) has also proposed a correction factor based the theoretical calculations of the sound reduction index described in Eq. (B.1) of Annex B of EN 12354 part 1 (ISO 15712 Part 1) (ISO, 2005a). The calculation references Josse and Lamure's (1964) calculations of the nonresonant and resonant sound transmission factors. The problem is that the equation has been derived using the equation of Josse and Lamure (1964) for the resonant radiation efficiency 
below the critical frequency while EN 12354 part 1 gives the equation of Leppington and Maidanik (1962; Vér and Holmer, 1971) for the resonant radiation efficiency below the critical frequency in Eq. (B.3.b). Because these two resonant radiation efficiencies differ by a factor which is significantly different from one, this inconsistency needs to be removed from the next revision of EN 13254 part 1 . Note that the non-resonant sound transmission loss is actually Sewell's theory and not the theory of Josse and Lamure. This is because EN 12354 part 1 sensibly uses Sewell's formula for the non-resonant radiation efficiency in Eq. (B.2). Because of the above concerns about Eq. (B.1) of EN 12354 part 1, the use of this method is not recommended.

\section{The correction factor of Nightingale and Bosmans}

Nightingale and Bosmans (2003) effectively used the Crocker and Price (1969) statistical energy analysis value of $r$ given in Eq. (10). They used the value of the resonant radiation efficiency derived by Craik (1996), Maidanik (1962; Vér and Holmer, 1971) and Leppington et al. (1987). The modification of Sewell's (1970) airborne diffuse field excited non-resonant radiation efficiency by Leppington et al. (1987) is used. The approximate correction factor of Leppington et al. (1987) and Sewell's (1970) is used to account for the approach to the critical frequency from below. The inclusion of this factor in the non-resonant sound transmission factor is surprising, since in statistical energy analysis (SEA), the effects of this factor are accounted for by the modal response. It is also surprising that they did not use the formula of Leppington et al. (1987) for the resonant sound transmission factor below the critical frequency. These problems highlight the difficulty of defining the resonant and the non-resonant sound transmission factors. The use of this correction factor is not recommended because it uses Sewell's approximate correction factor for the non-resonant sound transmission factor. 


\section{Direct theoretical calculation}

Another possibility is the direct theoretical calculation of the resonant sound transmission factor. Rindel (2007) and Lee and Ih (2004) effectively calculated the mean squared mass law velocity for unit incident intensity and multiplied it by $r$ given in Eq. (10) and the resonant radiation resistance. Equation (B.1) of Annex B of EN 12354 part 1 (ISO 15712 part 1) (ISO, 2005a) can be used to calculate the resonant sound transmission factor. Unfortunately, as noted in the discussion of the EN12354 Annex B correction factor (Sec. II B 4), the formula in the standard appears to be wrong.

The formula of Leppington et al. (1987) for $\tau_{r}$ can be used, but as noted above there is some doubt as to whether the separation into resonant and non-resonant parts is appropriate for the purpose of EN 12354. In particular, as noted in Sec. II B 5, Nightingale and Bosmans (2003) only used the non-resonant formula Leppington et al. and not the resonant formula.

\section{CSTB PREDICTION METHOD}

The third prediction method described in this paper emphasizes the importance of the radiation efficiencies of lightweight elements when applying flanking transmission predictions to frequencies below the critical frequency. Guigou-Carter et al. (2006) and Villot and GuigouCarter (2006) proposed and used this method to predict flanking transmission in a lightweight wooden building. The application of the CSTB method requires the measurement or the calculation of the airborne diffuse field excited radiation efficiency, the structure-borne diffuse field excited radiation efficiency and the direct sound transmission factor. These values are used in a modified version (Villot, 2002) of the flanking sound transmission factor that Gerretsen (1979) derived and as shown in Eq. (2) such that

$$
\tau_{i j}=\tau_{i} d_{a, i j} \frac{\sigma_{r, j}}{\sigma_{a, i}} \frac{S_{j}}{S_{0}} .
$$


where $\tau_{i}$ is the direct sound transmission factor of building element $i, d_{a, i j}$ is the airborne diffuse field excited vibration reduction factor which is a ratio of the mean square surface velocities of building elements $j$ and $i$ when building element $i$ is excited by diffuse airborne sound, and $\sigma_{a, i}$ is the radiation efficiency of building element $i$ when excited by diffuse airborne sound. The vibration reduction factor $d_{a, i j}$ accounts for the difference between the vibration levels of building elements $i$ and $j$ and is measured according to ISO 10848 (ISO, 2006). The ratio of radiation efficiencies corrects for the difference in radiation efficiencies of building elements $i$ and $j$ because of the different ways in which they are excited and their possible different constructions. The ratio of areas accounts for the difference between the radiating area of building element $j\left(S_{j}\right)$ and the area of the common building element between the two rooms $\left(S_{0}\right)$. The common building element is chosen as the reference area for all flanking sound transmission factor calculations so that they can be easily added together without further area corrections.

The average of the flanking sound transmission factors in both directions can be taken in order to reduce the experimental uncertainty. This paper uses the geometric mean so that it is compatible with the current EN12354 method above the critical frequency. Since the flanking sound transmission factor has a log-normal distribution probability density function (Mahn and Pearse, 2008a), the best estimate of the flanking transmission factor is

$$
\overline{\tau_{i j}}=\exp \left\{\ln \left(\sqrt{\tau_{i j} \tau_{j i}}\right)+\left[\ln \left(\sqrt{\frac{\tau_{i j}}{\tau_{j i}}}\right)\right]^{2}\right\} .
$$

If it is assumed that the difference between $\tau_{i j}$ and $\tau_{j i}$ is small, the squared term in Eq. (23) can be ignored and the equation can be rewritten as

$$
\tau_{C S T B} \approx \sqrt{\tau_{i j} \tau_{j i}}=\sqrt{\tau_{i} \tau_{j}} \sqrt{d_{a, i j} d_{a, j i}} \sqrt{\frac{\sigma_{r, i}}{\sigma_{a, i}} \frac{\sigma_{r, j}}{\sigma_{a, j}}} \frac{\sqrt{S_{i} S_{j}}}{S_{0}},
$$


which is also the geometric mean. The validity of the assumption that the difference between $\tau_{i j}$ and $\tau_{j i}$ is small can be determined calculating by calculating the difference between the true best estimate and the geometric mean which is equal to

$$
\frac{5}{2 \log _{10}(e)}\left[\log _{10}\left(\frac{\tau_{i j}}{\tau_{j i}}\right)\right]^{2} \mathrm{~dB} .
$$

The use of the CSTB prediction method will require the theoretical calculation or the measurement of the radiation efficiency terms. However, a standardized method of measuring the radiation efficiency currently does not exist. Villot and Guigou-Carter (Villot and GuigouCarter, 2006) have suggested that the radiation efficiency be determined according to

$$
10 \log _{10}(\sigma)=L_{p}-6-L_{v}+10 \log _{10}\left(\frac{A}{S}\right)
$$

where $L_{p}$ is the spatially averaged sound level radiated in the receiving room, $L_{v}$ is the spatially averaged vibration level of the element tested (of surface area $S$ ) and $A$ is the equivalent absorption area of the receiving room. $L_{v}$ can be measured using the same method as described for measuring $D_{v, i j}$ in ISO10848 using either airborne or mechanical sources of excitation.

However, the excitation of homogeneous elements using an electromagnetic shaker in order to measure the radiation efficiency can be problematic since the use of a point force to excite the element will produce a bending wave near field in the element. The bending wave near field radiated power is that which would be radiated if the building element were infinite in extent and the resonant or reverberant field radiated power is the power which is radiated due to reflections from the edges of the finite building element. At and above the critical frequency it is difficult to distinguish between these two forms of radiation and the correction is effectively zero. Below the critical frequency Fahy and Gardonio (2007) have shown that the ratio $e$ of the resonant radiated sound power $P_{r}$ to the bending wave near field radiated sound power $P_{n}$ is 


$$
e=\frac{P_{r}}{P_{n}}=\frac{\pi}{4} \frac{f_{c}}{f} \frac{\sigma_{r}}{\eta} .
$$

The measured power $P$ is the total radiated power which is the sum of the bending wave near field radiated power and the resonant radiated power. Since only the resonant radiated power is needed when calculating the resonant radiation efficiency, the following correction has to be applied.

$$
P_{r}=\frac{1}{1+1 / e} P
$$

FIG. 4 graphs the correction $1 /(1+1 / e)$ in $\mathrm{dB}$ for a $13 \mathrm{~mm}$ gypsum plaster board panel with a critical frequency of $3150 \mathrm{~Hz}$, a total damping loss factor of 0.03 , a height of $3 \mathrm{~m}$ and a width of $4 \mathrm{~m}$. This correction term is as expected negligible above the critical frequency but can be quite important below the critical frequency (up to $-3 \mathrm{~dB}$ for the considered case).

For single leaf homogeneous isotropic elements, an alternative method to avoid the extra point force radiation contribution is to measure the resonant radiation efficiency of a homogeneous element by exciting a second building element which is coupled to the building element under evaluation.

The extra point force radiation contribution is unlikely to be a problem for complex building elements if the radiation efficiency is measured for the non-excited face of the element. Since the point force does not act on the wall leaf radiating into the receiving room, then the only bending wave near fields in the radiating leaf will be those due to the structural connections.

\section{COMPARISON OF THE RADIATION EFFICIENCY AND THE EN12354 PREDICTION METHODS}

The theory behind the radiation efficiency method and the EN12354 method are described in the literature (Gerretsen, 1979; 1986; Villot and Guigou-Carter, 2006) and so will not be 
discussed further. However, some of the primary differences between the prediction methods are discussed in this section. It is important to note that both methods assume that the elements support diffuse vibratory fields and this is often not the case for lightweight building constructions, especially double-leaf constructions. Predictions using the direct approach described in Sec. I do not have this problem. Modifications to the EN12354 method to account for the non-diffuse vibratory fields such as the inclusion of the element attenuation have been proposed (Gerretsen, 2007).

\section{A. Velocity level difference}

The EN12354 method can be considered as a first order SEA approximation (Gerretsen, 2003) and therefore the equations describing the power balance can only consider the resonant transmission. Furthermore, it is assumed that only resonant transmission is important for flanking transmission (Gerretsen, 1979) which is an acceptable assumption for heavy, monolithic constructions with critical frequencies below the frequency range of interest, but not for lightweight constructions. EN12354 uses the vibration reduction factor measured in accordance with ISO10848 to describe the vibrational power transmission through the junction between the elements. Although ISO10848 describes the measurement of the vibration reduction factor by excitation of the elements using airborne noise, it is noted that the use of mechanical excitation is preferred since airborne noise will excite both resonant and non-resonant velocity on the source element $i$ such that

$$
v_{a, i}^{2}=v_{r, i}^{2}+v_{n r, i}^{2} .
$$

Note that Eq. (29) is identical to Eq. (8). The use of mechanical excitation will result in only resonant velocity on the elements and therefore, the spatially averaged mean square velocity 
measured on the receiving element $j$ when the source element $i$ is excited using mechanical excitation is:

$$
v_{r, j}^{2}=d_{r, i j} v_{r, i}^{2} .
$$

Note that Eq. (30) is identical to Eq. (3).

Alternatively, the CSTB method makes no assumptions about the exclusion of the transmission of the non-resonant velocity through the junction. The airborne excited vibration reduction factor is used to describe the transmission of the vibration through the junction between the elements $i$ and $j$ such that:

$$
v_{r, j}^{2}=d_{a, i j}\left(v_{r, i}^{2}+v_{n r, i}^{2}\right)
$$

Note that the response of the receiving element $j$ is purely resonant due to the resonant and nonresonant velocity on the source element.

Above the critical frequency of an element, the airborne excited and the resonant radiation efficiencies of the element are equal (Craik, 2003). Thus above the critical frequencies of both building elements, Eq. (24) of the CSTB approach reduces to the following equation.

$$
\tau_{C S T B, f \geq f_{c}}=\sqrt{\tau_{i} \tau_{j}} \sqrt{d_{a, i j} d_{a, j i}} \frac{\sqrt{S_{i} S_{j}}}{S_{0}} \text { if } f \geq f_{c}
$$

Above the critical frequency, the airborne excited and mechanically excited vibration reduction factors are equal and the total sound transmission factor is equal to the resonant sound transmission factor. Therefore, above the critical frequency Eq. (32) is essentially the same as Eq. (4) used by the EN12354 method above the critical frequency.

\section{B. Radiation efficiencies}


As previously mentioned, the EN12354 method only considers the resonant component of the mean square velocity on an element $i$ and therefore uses the corresponding resonant radiation efficiency.

On the contrary, the CSTB method is more general since it takes into account both the resonant and the non-resonant components of the mean square velocity excited on an element by airborne excitation. Therefore, the radiation efficiency used to describe the airborne excitation of an element $i$ is the airborne diffuse field excited radiation efficiency inclusive of both the resonant and non-resonant components.

As previously discussed, below the critical frequency of an element $i$, it is more appropriate to consider both the resonant and the non-resonant fields propagating in that element. Above the critical frequency, the CSTB and the EN12354 methods are equivalent since the resonant field dominates the propagation in the structural element.

Furthermore, the resonant radiation efficiency and airborne diffuse field excited radiation efficiency of an element $i$ are very different below the critical frequency (see Villot and GuigouCarter (2006)) : their variation with respect to frequency presents quite different slopes, and the airborne diffuse field excited radiation efficiency is larger than the resonant radiation efficiency (the difference reduces as the critical frequency is approached). Thus, it is important to use the appropriate radiation efficiency for the predictions.

\section{Resonant sound reduction index versus radiation efficiency}

The EN12354 method includes the calculation of the resonant sound reduction index of the elements. Unlike the values of the radiation efficiencies, the resonant sound reduction index can not be directly measured. This has the serious consequence that the errors associated with the calculation of the resonant sound reduction index can not be quantified. This problem shows the 
advantage of using the radiation efficiencies since these quantities can be measured in the laboratory. The measured values of the radiation efficiency can be compared against the values calculated theoretically so that the error in the calculations is known and the models can be improved.

Furthermore, since the ratio of the resonant to the non-resonant mean squared velocities and the ratio of the non-resonant to the resonant radiation efficiency are needed to calculate the correction factors used to calculate the resonant sound reduction index, there seems to be no advantage to using a correction factor in the EN12354 method compared to the use of the radiation efficiencies in the CSTB method.

\section{VIBRATION REDUCTION FACTOR APPROXIMATIONS}

Since $d_{r, i j}$ is what was required for the use of the EN12354 method, ISO10848 currently recommends the measurement of $d_{r, i j}$ instead of $d_{a, i j}$, although both measurement methods are described in the standard. Since a few laboratories including the Belgium Building Research Institute have been collecting $d_{r, i j}$ data (Crispin et al., 2006), it would be beneficial to use the measured data in the CSTB prediction method. The possibility that $d_{r, i j}$ can be assumed to be equal to $d_{a, i j}$ will be discussed in this section. The discussion is based largely on theory and future experimental data is required to determine the possible errors in the prediction if the assumption is applied.

\section{A. Assumption that airborne and resonant vibration reduction factors are equal}

The airborne vibration reduction factor $d_{a, i j}$ includes both the resonant and non-resonant velocity components from the source element. If $d_{r, i j}$ data is to be used in place of $d_{a, i j}$, then some assumptions must be made. According to Villot (2002) and Guigou-Carter et al. (2006), $d_{r, i j}$ is of the order of $2 \mathrm{~dB}$ greater than $d_{a, i j}$. However, if the emission plate is the inner leaf of a steel stud 
cavity wall with sound absorbing material in the cavity, this difference can reach $5 \mathrm{~dB}$ at frequencies close to the mass-air-mass resonance (Villot, 2002).

The validity of the assumption that $d_{a, i j}$ can be replaced by $d_{r, i j}$ was examined through measurements from CSTB. The ratio of $\left(\sigma_{n r}-\sigma_{a}\right) /\left(\sigma_{n r}-\sigma_{r}\right)$ from Eq. (14) is plotted versus frequency in FIG. 1 for a single leaf $13 \mathrm{~mm}$ gypsum plaster board wall mounted on wood studs $\left(9 \mathrm{~kg} / \mathrm{m}^{2}\right.$ with $f_{c} \approx 3150 \mathrm{~Hz}$ ) measuring 4.18 by $2.47 \mathrm{~m}$. If $d_{a, i j}=d_{r, i j}$ then the ratio plotted in the figure would be equal to 1 , i.e. $0 \mathrm{~dB}$. FIG. 1 shows that for the plaster board wall $d_{a, i j}$ differed from $d_{r, i j}$ by between -2.7 and $0.6 \mathrm{~dB}$ if Sewell's theory or the spatial windowing technique was used to calculate the non-resonant radiation efficiency. FIG. 2 presents the same information as FIG. 1 but for a double layer single leaf wall made of $13 \mathrm{~mm}$ gypsum plaster board $\left(9 \mathrm{~kg} / \mathrm{m}^{2}\right.$ with $f_{c} \approx$ $3150 \mathrm{~Hz})$ and $16 \mathrm{~mm}$ OSB $\left(10 \mathrm{~kg} / \mathrm{m}^{2}\right.$ with $\left.f_{c} \approx 1600 \mathrm{~Hz}\right)$ and mounted on wood studs. FIG. 2 reveals that $d_{a, i j}$ differs from $d_{r, i j}$ by between -7.0 and $0.0 \mathrm{~dB}$ if Sewell's theory or the spatial windowing technique was used to calculate the non-resonant radiation efficiency. FIG. 3 displays the same information as FIG. 1 and FIG. 2, but for a wooden floor made of $22 \mathrm{~mm}$ chipboard on I beam joists $\left(14 \mathrm{~kg} / \mathrm{m}^{2}\right.$ with $\left.f_{c} \approx 2000 \mathrm{~Hz}\right)$. FIG. 3 shows that $d_{a, i j}$ differs from $d_{r, i j}$ by between 1.1 and $0.8 \mathrm{~dB}$ if Sewell's theory or the spatial windowing technique was used to calculate the non-resonant radiation efficiency in the frequency range from 50 to $630 \mathrm{~Hz}$. It is certainly not possible to deduce from the results that $d_{a, i j}=d_{r, i j}$ but in these frequency ranges it can be seen that $d_{a, i j}$ and $d_{r, i j}$ are close.

The velocity level difference $D_{v, i j}$ in $\mathrm{dB}$ between building elements $i$ and $j$ when element $i$ is excited is

$$
D_{v, i j}=10 \log _{10}\left(\frac{1}{d_{v, i j}}\right)=-10 \log _{10}\left(d_{v, i j}\right) .
$$


FIG. 5 and FIG. 6 show comparisons by Mahn of the velocity level differences for a $1.6 \mathrm{~mm}$ thick L shaped steel panel and for a $4 \mathrm{~mm}$ L shaped MDF panel measured using mechanical excitation and using diffuse field airborne excitation, both in accordance with ISO10848. Each of the elements of the L shaped panels had a width and height of 0.948 and $1.548 \mathrm{~m}$. The steel elements were joined by being spot welded to an angle iron. The MDF elements were glued and screwed to a $25.4 \mathrm{~mm}$ square wooden bar. The airborne excitation was from a $217 \mathrm{~m}^{3}$ reverberation room. The error bars in the figures are the $95 \%$ confidence intervals which were calculated using the method described in Mahn and Pearse (2009).

The figures show that in the case of the steel L panel the $95 \%$ confidence intervals of $d_{r, i j}$ and $d_{a, i j}$ overlap over most of the frequency range. Therefore, $d_{r, i j}$ is not statistically different than $d_{a, i j}$ with the exception of the $1250 \mathrm{~Hz} 1 / 3$ octave band. However, given the large confidence intervals due to the non-diffuse vibratory fields measured on the elements, the overlap of the confidence intervals is not itself conclusive. In the case of the MDF panel, in the frequency range from $25 \mathrm{~Hz}$ to $4 \mathrm{kHz}, d_{r, i j}$ is not statistically different at the $95 \%$ level from $d_{a, i j}$ at 16 of the third octave band center frequencies and is statistically significantly less at the other 9 third octave band center frequencies at the $95 \%$ confidence level. For the third octave band center frequencies from 5 to $10 \mathrm{kHz}, d_{r, i j}$ is statistically greater at the $95 \%$ level than $d_{a, i j}$. In general, conclusions drawn from results presented in FIG. 5 and FIG. 6 differ from those deduced from the results from CSTB data presented in FIG. 1, FIG. 2 and FIG. 3.

\section{B. Assumption that non-resonant vibration transmission through building element junction is negligible}

A possible alternative assumption is that the contribution of the non-resonant vibration in building element $i$ to the transmission of vibration to building element $j$ is very much smaller 
than the contribution of the resonant vibration in building element $i$. The use of this approximation is based on the finding that non-resonant waves do not seem to significantly contribute to the vibration transmission through junctions between lightweight plates with stiffeners (Villot and Guigou-Carter, 2000). This assumption is necessary in order to be able to justify the use of resonant sound transmission factors.

With this assumption, the mean square velocity on element $j$ due to the excitation of element $i$ becomes

$$
v_{j}^{2}=d_{a, j i} v_{a, i}^{2} \approx d_{r, i j} v_{r, i}^{2} .
$$

The last equality in Eq. (34) can be written as (Villot, 2002)

$$
d_{a, i j}=d_{r, i j} \frac{v_{r, i}^{2}}{v_{a, i}^{2}} .
$$

Using Eq. (14),Eq. (35) becomes

$$
\frac{d_{a, i j}}{d_{r, i j}}=\frac{v_{r, i}^{2}}{v_{a, i}^{2}}=\frac{\sigma_{n r, i}-\sigma_{a, i}}{\sigma_{n r, i}-\sigma_{r, i}} .
$$

Equations (35) or (36) can be used to approximate $d_{r, i j}$ as $d_{a, i j}$ for use in Eq. (24). Unfortunately, as shown in FIG. 1, FIG. 2 and FIG. 3, the experimental use of Eq. (36) can produce nonphysical negative values which cannot be converted to decibels.

\section{The resonant sound transmission factor}

It is assumed that the resonant sound transmission factor $\tau_{r, i}$ of building element $i$ can be calculated using the following equation.

$$
\tau_{r, i}=\tau_{i} \frac{v_{r, i}^{2}}{v_{a, i}^{2}} \frac{\sigma_{r, i}}{\sigma_{a, i}} .
$$

Equations (22), (35) and (37) can be combined to produce Eq. (2). Therefore, if it is assumed that the non-resonant transmission through the junction is negligible which is an 
assumption of the EN12354 method and that Eq. (49) is valid for calculating the resonant sound reduction index, then it must also be assumed that equations (2) and (24) are equivalent.

\section{Additional assumption that non-resonant vibration is not a significant contributor to total velocity}

If it is also assumed that the mean squared non-resonant velocity is very much smaller than the mean squared resonant velocity, Eq. (7) becomes

$$
v_{a}^{2} \approx v_{r}^{2}
$$

Inserting Eq. (38) into equations (34) and (35) gives

$$
v_{j}^{2}=d_{a, i j} v_{a, i}^{2} \approx d_{r, i j} v_{a, i}^{2}
$$

and

$$
d_{a, i j} \approx d_{r, i j}
$$

Thus, the combination of assumptions that the non-resonant transmission through the junction is negligible and that the non-resonant velocity is not a significant contributor to the total velocity results in the assumption that the airborne noise excited and the mechanically excited vibration reduction factors are equal. As stated in Sec. VI A, the validity of these assumptions and conclusions still needs experimental verification.

\section{CONCLUSIONS}

The prediction method recommended by this paper is the CSTB approach which makes use of the airborne and resonant radiation efficiencies. The airborne diffuse field excited radiation efficiency and the resonant radiation efficiency should be measured or calculated theoretically as well as the direct sound transmission factors. This data should be used with the CSTB approach. If the airborne diffuse field excited velocity reduction factor has been measured, no assumption is needed. If the resonant velocity reduction factor has been measured, the assumption that the 
airborne diffuse field excited velocity reduction factor is approximately equal to the resonant velocity reduction factor needs to be made. Further work is needed to quantify the errors in the predictions associated with the application of this assumption. Alternatively, the CSTB correction factor can be used to predict the flanking transmission factor using the EN13254

method. However, the calculation of the resonant transmission factor using this method requires the assumptions that the transmission of non-resonant velocity through the junction is insignificant compared to the resonant velocity, the non-resonant radiation efficiency is equal to one or that the total and resonant radiation efficiencies are much less than the non-resonant radiation efficiency.

If the CSTB method is recommended for the predictions, it should be stressed that it still can probably be improved; more experimental data is definitely required. Indeed, theoretical predictions of the airborne diffuse field sound excited and the resonant radiation efficiencies and the direct sound transmission factors should be compared with the measured values to aid the development of suitable theoretical prediction methods. If the revision of EN 12354 maintains the use of resonant sound transmission factors, it should specify exactly how to determine them. For a multiple leaf element, it should also specify when to use the complete element and when to use just one leaf of the element.

\section{REFERENCES}

Brunskog, J., and Chung, H. (2011). "Non-diffuseness of vibration fields in ribbed plates," J. Acoust. Soc. Am. 129, 1336-1343.

Craik, R. J. M. (1996). Sound transmission through buildings using statistical energy analysis (Gower Publishing Limited, Aldershot), p. 91. 
Craik, R. J. M. (2003). "Non-resonant sound transmission through double walls using statistical energy analysis," Appl. Acoust. 64, 325-341.

Cremer, L., and Heckl, M. (1973). Structure-borne sound - Structural vibrations and sound radiation at audio frequencies (Springer-Verlag, Berlin), p. 533.

Crispin, C., Ingelaere, B., Van Damme, M., and Wuyts, D. (2006). "The Vibration Reduction Index Kij: Laboratory Measurements for Rigid Junctions and for Junctions With Flexible Interlayers," Build. Acoust. 13, 99-112.

Crocker, M. J., and Price, A. J. (1969). "Sound transmission using statistical energy analysis," J. Sound Vib. 9, 469-486.

Davy, J. L. (2009). "The forced radiation efficiency of finite size flat panels which are excited by incident sound," J. Acoust. Soc. Am. 126, 694-702.

Fahy, F., and Gardonio, P. (2007). Sound and structural vibration : radiation, transmission and response (Elsevier, Amsterdam), p. 94.

Gerretsen, E. (1979). "Calculation of the sound-transmission between dwellings by partitions and flanking structures," Appl. Acoust. 12, 413-433.

Gerretsen, E. (1986). "Calculation of airborne and impact sound insulation between dwellings," Appl. Acoust. 19, 245-264.

Gerretsen, E. (2003). "Prediction of sound insulation in buildings: a tool to improve the acoustic quality," in Proceeedings of Jahrestagung Fur Akustik (Aachen, Germany), pp. 1-6.

Gerretsen, E. (2007). "Some aspects to improve sound insulation prediction models for lightweight elements," in Inter-noise 2007 (Istanbul, Turkey), pp. 1-10. 
Guigou-Carter, C., Villot, M., and Wetta, R. (2006). "Prediction method adapted to wood frame lightweight constructions," Build. Acoust. 13, 173-188.

Hongisto, V. (2001). "Case study of flanking transmission through double structures," Appl. Acoust. 62, 589-599.

ISO (1991). "ISO 140-2:1991 Acoustics -- Measurement of sound insulation in buildings and of building elements -- Part 2: Determination, verification and application of precision data," (International Organization for Standardization, Geneva, Switzerland), pp. 1-13.

ISO (2003). "ISO 15186-2:2003 Acoustics -- Measurement of sound insulation in buildings and of building elements using sound intensity -- Part 2: Field measurements," (International Organization for Standardization, Geneva, Switzerland), pp. 1-25.

ISO (2005a). "ISO 15712-1:2005(E) Building acoustics - Estimation of acoustic performance of buildings from the performance of elements - Part 1: Airborne sound insulation between rooms," (International Organization for Standardization, Geneva, Switzerland), pp. 1-59.

ISO (2005b). "ISO 15712-2:2005(E) Building acoustics - Estimation of acoustic performance of buildings from the performance of elements - Part 2: Impact sound insulation between rooms," (International Organization for Standardization, Geneva, Switzerland), pp. 1-30.

ISO (2006). "ISO 10848-1:2006 Acoustics -- Laboratory measurement of the flanking transmission of airborne and impact sound between adjoining rooms -- Part 1: Frame document," (International Organization for Standardization, Geneva, Switzerland), pp. 1-25.

Josse, R., and Lamure, J. (1964). "Transmission du son par une paroi simple (Sound transmission through a single wall)," Acust. 14, 266-280. 
Lee, J. H., and Ih, J. G. (2004). "Significance of resonant sound transmission in finite single partitions," J. Sound Vib. 277, 881-893.

Leppington, F. G., Broadbent, E. G., and Heron, K. H. (1982). "The acoustic radiation efficiency of rectangular panels," Proc. R. Soc. London, Ser. A 382, 245-271.

Leppington, F. G., Heron, K. H., Broadbent, E. G., and Mead, S. M. (1987). "Resonant and nonresonant acoustic properties of elastic panels .2. The transmission problem," Proc. R. Soc. London, Ser. A 412, 309-337.

Mahn, J. P. (2010). "Erratum: "Separation of resonant and non-resonant components-Part I: Sound reduction index," Build. Acoust. 18, 245-246.

Mahn, J. P., and Pearse, J. (2008a). "On the Probability Density Functions of the Terms Described by the EN12354 Prediction Method," Build. Acoust. 15, 263-287.

Mahn, J. P., and Pearse, J. (2008b). "Separation of resonant and non-resonant components—Part I: Sound reduction index," Build. Acoust. 15, 95-115.

Mahn, J. P., and Pearse, J. (2009). "On the Uncertainty of the EN12354-1 Estimate of the Flanking Sound Reduction Index Due to the Uncertainty of the Input Data," Build. Acoust. 16, 199-231.

Mahn, J. P., and Stevenson, D. C. (2008). "Separation of resonant and non-resonant componentsPart II: Surface velocity," Build. Acoust. 15, 117-135.

Maidanik, G. (1962). "Response of ribbed panels to reverberant acoustic fields," J. Acoust. Soc. Am. 34, 809-826.

Maidanik, G. (1975). "Erratum: "Response of ribbed panels to reverberant acoustic fields"," J. Acoust. Soc. Am. 57, 1552. 
Metzen, H. A. (2004). "Radiation factor correction when calculating flanking transmission " in DAGA 2004 (Strasbourg, France), pp. 1-2.

Nightingale, T. R. T. (1995). "Application of the CEN draft building acoustics prediction model to a lightweight double leaf construction," Appl. Acoust. 46, 265-284.

Nightingale, T. R. T., and Bosmans, I. (2003). "Expressions for first-order flanking paths in homogeneous isotropic and lightly damped buildings," Acta Acust. Acust. 89, 110-122.

Quirt, J. D. (2009). "Controlling air-borne and structure-borne sound in buildings," in Inter-noise 2009, edited by B. Gover, J. S. Bolton, C. Burroughs, and G. C. Maling Jr. (Ottawa, Canada), pp. $4360-4374$.

Rindel, J. H. (2007). "Sound insulation in buildings," (Ørsted•DTU, Acoustic Technology, Technical University of Denmark, Lyngby), pp. 1-368.

Rudder, F. F. (1985). "Airborne sound transmission loss characteristics of wood-frame construction," (Forest Products Laboratory, Madison), pp. 1-27.

Sewell, E. C. (1970). "Transmission of reverberant sound through a single-leaf partition surrounded by an infinite rigid baffle," J. Sound Vib. 12, 21-32.

Vér, I. L., and Holmer, C. I. (1971). "Interaction of sound waves with solid structures," in Noise and Vibration Control, edited by L. L. Beranek (McGraw-Hill, New York), pp. 270-361. Villot, M. (2002). "Modeling flanking transmissions in lightweight constructions," in Forum Acustica 2002 (Seville, Spain), pp. 1-6.

Villot, M., and Guigou-Carter, C. (2000). "Contribution of forced and resonant vibration in sound transmission through partitions and in vibration transmission through plate junctions," in NOVEM 2000 (Lyon, France), pp. 1-10. 
Villot, M., and Guigou-Carter, C. (2006). "Measurement methods adapted to wood frame lightweight constructions," Build. Acoust. 13, 189-198.

Villot, M., Guigou, C., and Gagliardini, L. (2001). "Predicting the acoustical radiation of finite size multi-layered structures by applying spatial windowing on infinite structures," J. Sound Vib. 245, 433-455.

\section{FIGURE CAPTIONS}

FIG. 1. (Color online) The ratio $\left(\sigma_{n r}-\sigma_{a}\right) /\left(\sigma_{n r}-\sigma_{r}\right)$ of Eq. (14) for a single leaf $13 \mathrm{~mm}$ gypsum plaster board wall mounted on wood studs $\left(9 \mathrm{~kg} / \mathrm{m}^{2}\right.$ with $\left.f_{c} \approx 3150 \mathrm{~Hz}\right)$ measuring 4.18 by 2.47 m. $\sigma_{n r}$ has been calculated by setting it to the value one $\diamond$, by using the theory of (Sewell, 1970) - and by using the spatial windowing technique (Villot et al., 2001) $\boldsymbol{\Delta}$. Unlike in EN 12354 (ISO, 2005a), the radiation efficiency has not been limited to a maximum of 2 .

FIG. 2. (Color online) The ratio $\left(\sigma_{n r}-\sigma_{a}\right) /\left(\sigma_{n r}-\sigma_{r}\right)$ of Eq. (14) for a double layer single leaf wall made of $13 \mathrm{~mm}$ gypsum plaster board $\left(9 \mathrm{~kg} / \mathrm{m}^{2}\right.$ with $\left.f_{c} \approx 3150 \mathrm{~Hz}\right)$ and $16 \mathrm{~mm} \mathrm{OSB}\left(10 \mathrm{~kg} / \mathrm{m}^{2}\right.$ with $f_{c} \approx 1600 \mathrm{~Hz}$ ) and mounted on wood studs measuring 4.18 by $2.47 \mathrm{~m}$. $\sigma_{n r}$ has been

calculated by setting it to the value one $\diamond$, by using the theory of (Sewell, 1970) $\boldsymbol{\square}$ and by using the spatial windowing technique (Villot et al., 2001) $\boldsymbol{\Delta}$. Unlike in EN 12354 (ISO, 2005a), the radiation efficiency has not been limited to a maximum of 2 .

FIG. 3. (Color online) The ratio $\left(\sigma_{n r}-\sigma_{a}\right) /\left(\sigma_{n r}-\sigma_{r}\right)$ of Eq. (14) for a wooden floor made of $22 \mathrm{~mm}$ chipboard on I beam joists $\left(14 \mathrm{~kg} / \mathrm{m}^{2}\right.$ with $\left.f_{c} \approx 2000 \mathrm{~Hz}\right)$ measuring 4.2 by $3.6 \mathrm{~m} . \sigma_{n r}$ has been calculated by setting it to the value one $\diamond$, by using the theory of (Sewell, 1970) $\mathbf{\square}$ and by using the spatial windowing technique (Villot et al., 2001) $\boldsymbol{\Delta}$. Unlike in EN 12354 (ISO, 2005a), the radiation efficiency has not been limited to a maximum of 2 .

FIG. 4. The correction factor in $\mathrm{dB}$ to convert from the mechanically point excited radiation efficiency to the resonant radiation efficiency for a $13 \mathrm{~mm}$ gypsum plaster board panel with a 
critical frequency of $3150 \mathrm{~Hz}$, a total damping loss factor of 0.03 , a height of $3 \mathrm{~m}$ and a width of $4 \mathrm{~m}$.

FIG. 5. Comparison of the velocity level difference for an L shaped $1.6 \mathrm{~mm}$ thick steel panel measured using structure-borne excitation and using airborne excitation. The error bars represent the $95 \%$ confidence limits.

FIG. 6. Comparison of the velocity level difference for a $4 \mathrm{~mm}$ thick L shaped medium density fibre (MDF) panel measured using structure-borne excitation and using airborne excitation. The error bars represent the $95 \%$ confidence limits. 


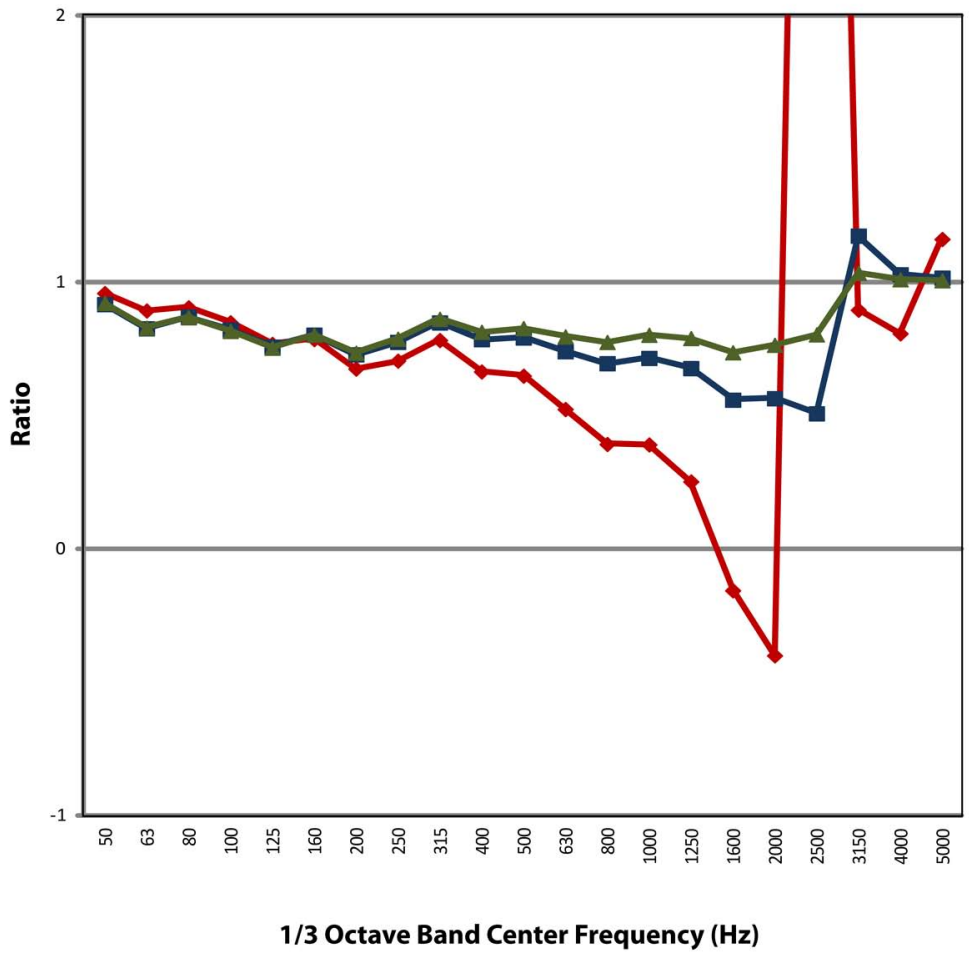




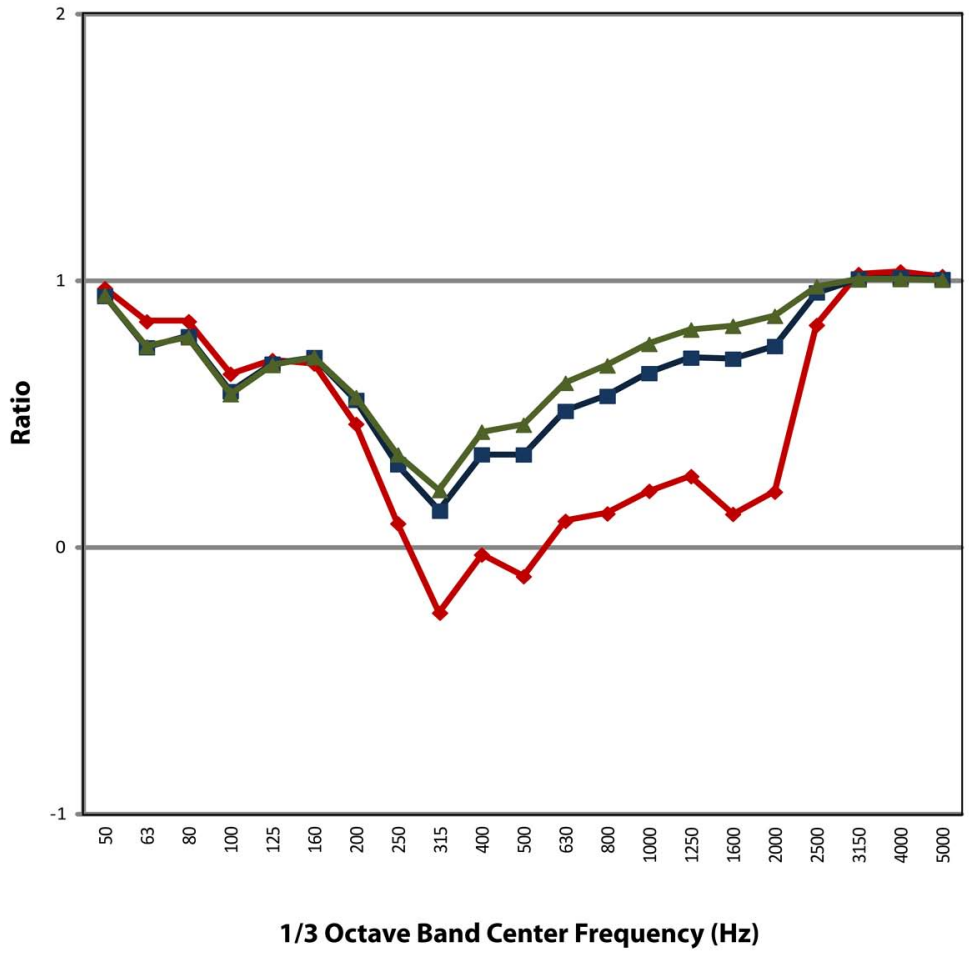




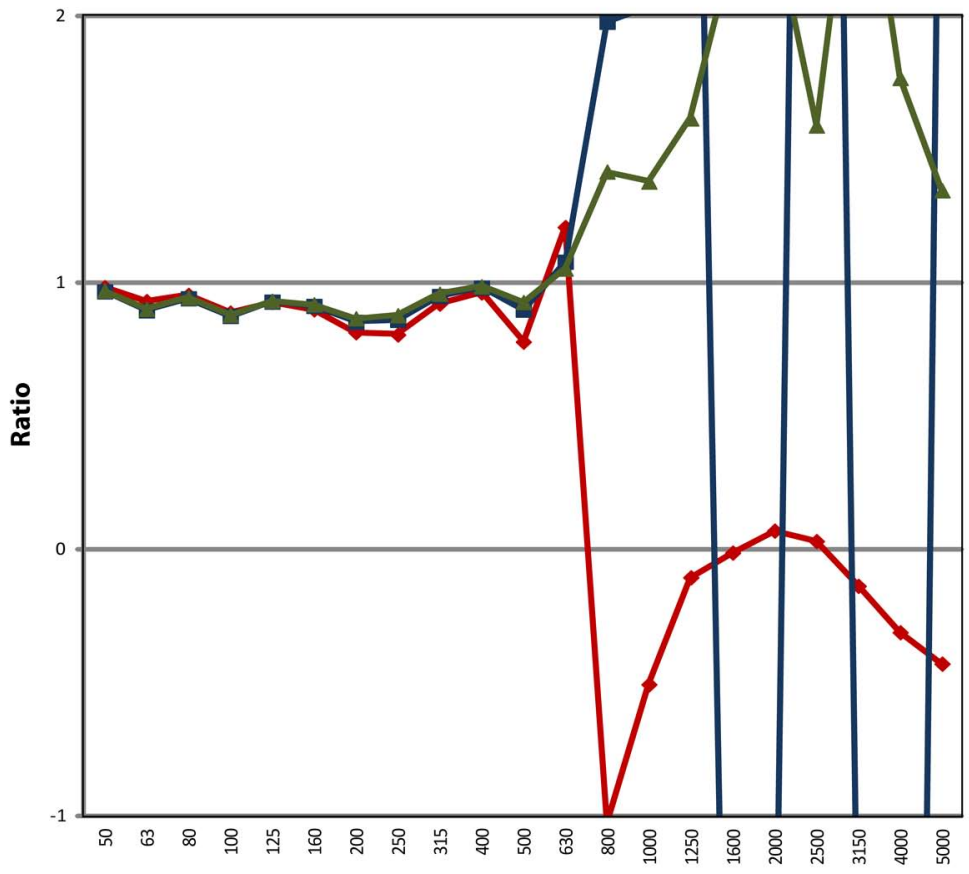

1/3 Octave Band Center Frequency (Hz) 


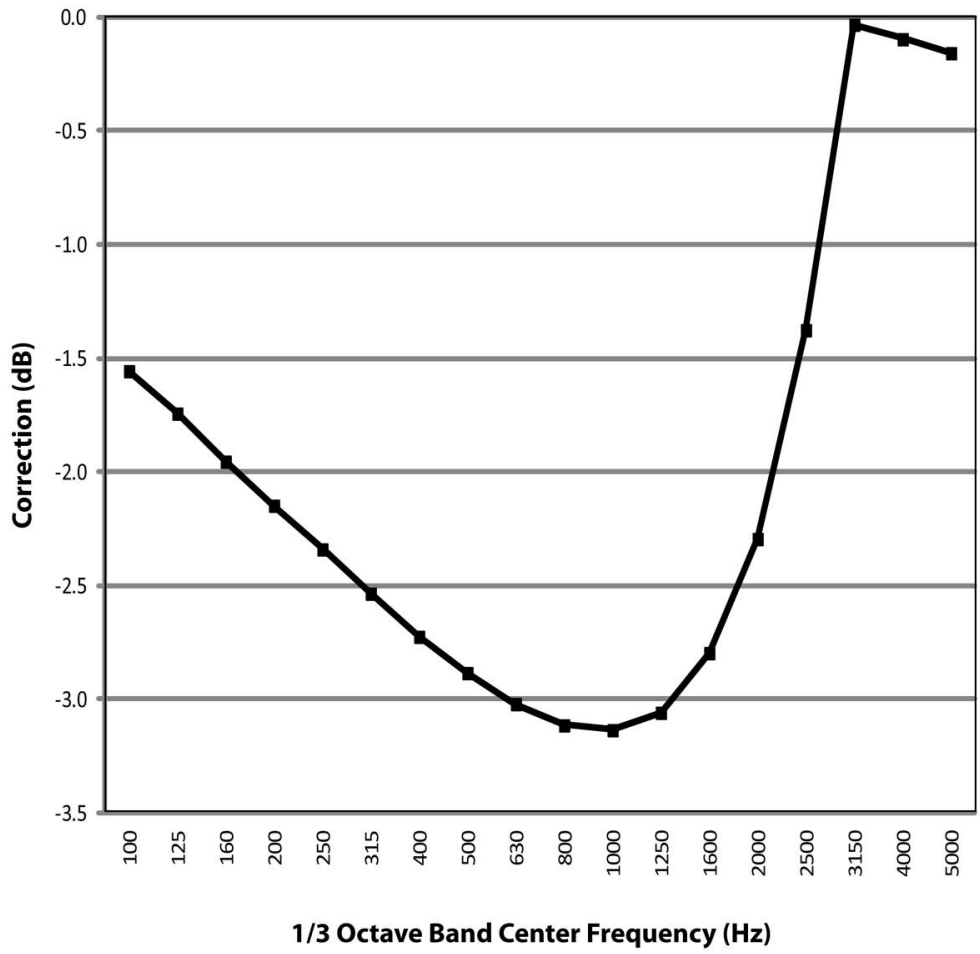


Velocity Level Difference Comparison - Steel L Panel

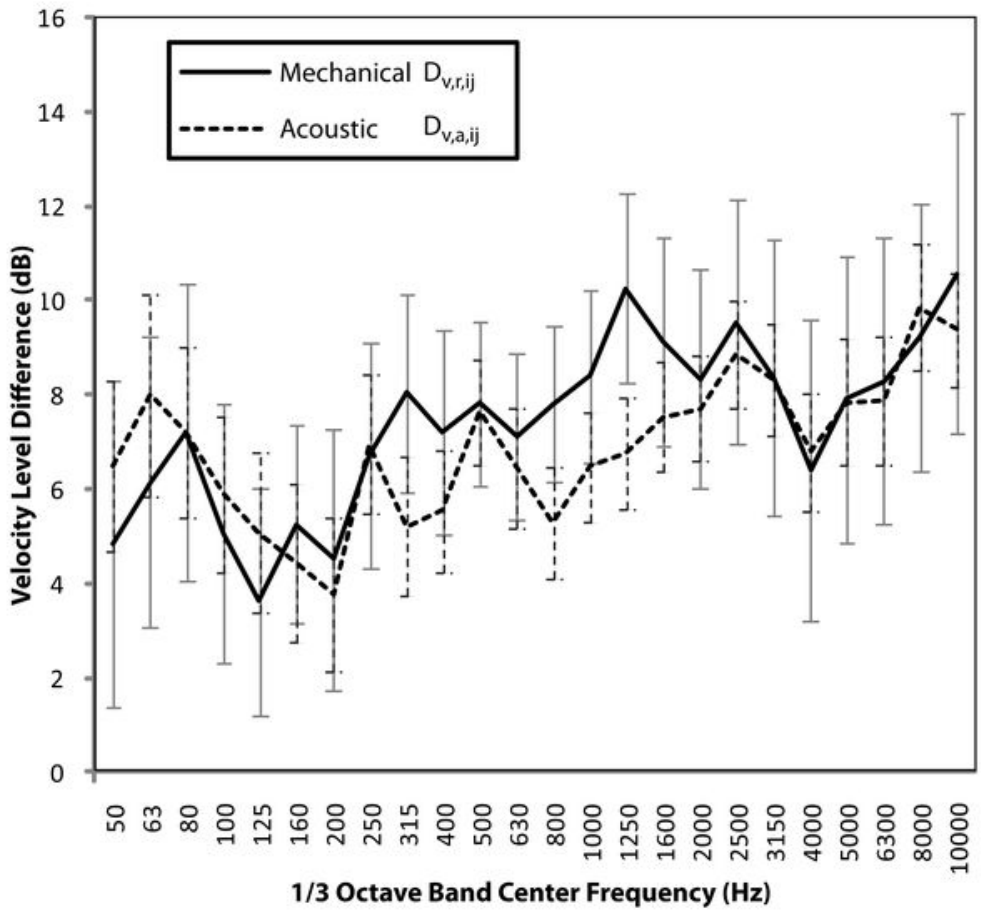


Velocity Level Difference Comparison - MDF L Panel

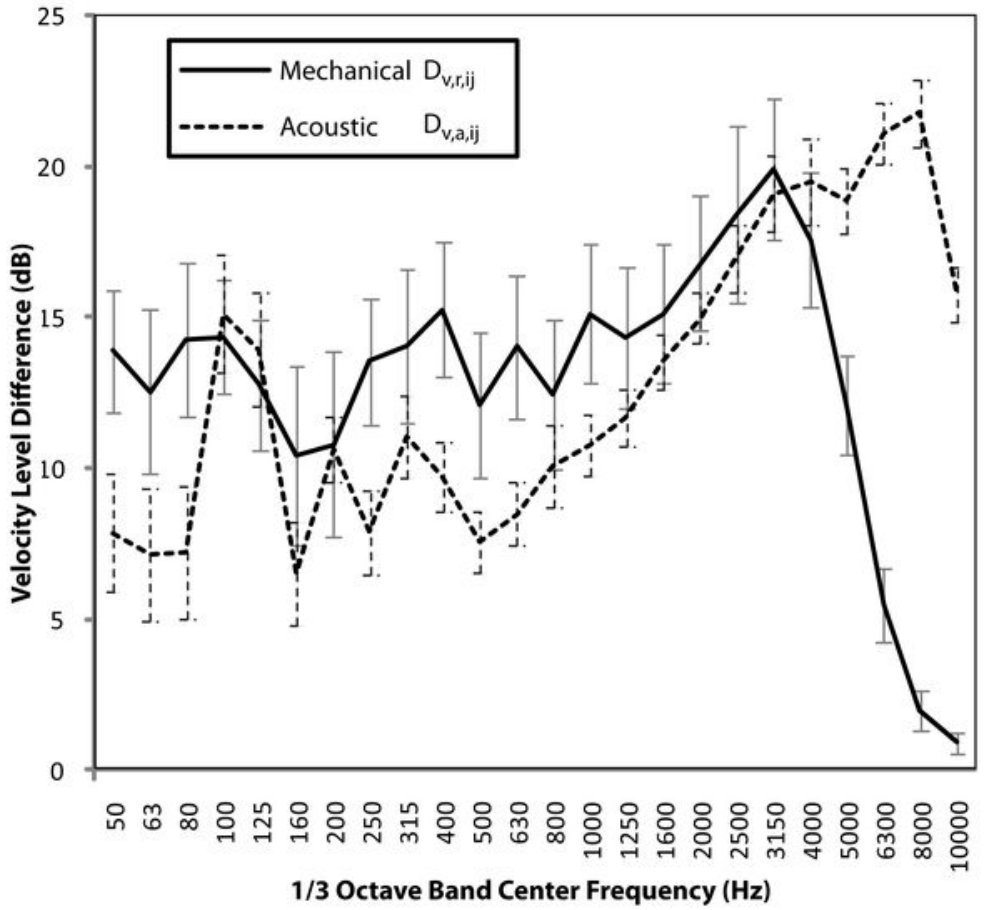

